\title{
Effect of antiviral therapy in reducing perinatal transmission of hepatitis B virus and maternal outcomes after discontinuing them
}

\author{
Kwang Il Seo', Si Hyun Bae ${ }^{2,3}$, Pil Soo Sung ${ }^{2,3}$, Chung-Hwa Park ${ }^{2}$, Hae Lim Lee ${ }^{2}$, Hee Yeon Kim², Hye Ji Kim², \\ Bo Hyun Jang ${ }^{2}$, Jeong Won Jang ${ }^{2,3}$, Seung Kew Yoon ${ }^{2,3}$, Jong Young Choi ${ }^{2,3}$, In-Yang Park ${ }^{4}$, Juyoung Lee ${ }^{5}$, \\ Hyun Seung Lee ${ }^{5}$, Sa-Jin Kim ${ }^{4}$, Jung Hyun Kwon ${ }^{2}$, U Im Chang ${ }^{2}$, Chang Wook Kim², Se Hyun Jo ${ }^{2}$, Young Lee ${ }^{4}$, \\ Fisseha Tekle ${ }^{6}$, and Jong-Hyun $\mathrm{Kim}^{5}$ \\ 'Department of Internal Medicine, Kosin University College of Medicine, Busan; ${ }^{2}$ Department of Internal Medicine, ${ }^{3}$ The Catholic \\ University Liver Research Center and WHO Collaborating Center of Viral Hepatitis, ${ }^{2}$ Department of Obstetrics and Gynecology, and \\ ${ }^{5}$ Department of Pediatrics, College of Medicine, The Catholic University of Korea, Seoul, Korea; ${ }^{6}$ Department of Gastroentrology and \\ Hepatology, St. Paul's Hospital Millennium Medical College, Addis Ababa, Ethiopia
}

Background/Aims: There have been numerous efforts to reduce mother-to-child transmission (MTCT) of hepatitis B virus (HBV) with antiviral agents during pregnancy. However, there are limited data regarding the outcomes of pregnant women after delivery. This study was performed to evaluate the efficacy of antiviral agents in preventing MTCT of HBV and maternal long-term outcomes.

Methods: The HBV-infected pregnant women treated with antiviral agents to prevent MTCT were retrospectively reviewed. Forty-one pregnant women who received telbivudine or tenofovir during late pregnancy (28-34 week) were analyzed. Hepatitis B virus surface antibody (HBsAb) positivity was tested in 43 infants after 7 months of birth. Eleven mothers were followed $>1$ year after delivery.

Results: The mean HBV DNA titer before antiviral therapy was 8.67 (6.60-9.49) log copies $/ \mathrm{mL}$, and the median age at delivery was 32 years (range, 22-40). Eleven patients were treated with tenofovir and 30 with telbivudine. The median duration was 57 days (range, 23-100), and the median HBV DNA titer at birth was 5.06 log copies $/ \mathrm{mL}$ (range, 2.06-6.50). Antiviral treatments were associated with significant HBV DNA reduction $(P<0.001)$. Among 43 infants (two cases of twins), $\mathrm{HBsAb}$ was not detected in two, subsequently confirmed to have HBV infection. Biochemical flare was observed in two of 11 mothers followed $>12$ months, and an antiviral agent was administered.

Conclusions: Antiviral treatment during late pregnancy effectively reduced MTCT. Long-term follow-up should be required in such cases. In addition, given that maternal biochemical flare occurred in $18 \%$ of mothers, re-administration of antiviral agents might be required. (Clin Mol Hepatol 2018;24:374-383)

Keywords: Mother-to-child transmission; Hepatitis B virus; Pregnancy; Antiviral agents; Postpartum

\section{Abbreviations:}

$A L T$, alanine aminotransferase; $C H B$, chronic hepatitis $B ; C$, caesarean section; $G A$, gestational age; $\mathrm{HBeAg}$, hepatitis $B$ e antigen; $H B s A b$, hepatitis $B$ virus surface antibody; HBV, hepatitis B virus; MTCT, mother-to-child transmission

\section{Corresponding author : Si Hyun Bae}

Department of Internal Medicine, Seoul St. Mary’s Hospital, College of Medicine, The Catholic University of Korea, 222 Banpo-daero, Seocho-gu, Seoul 06591, Korea

Tel: +82-2-2258-2073, Fax: +82-2-3481-4025

E-mail: baesh@catholic.ac.kr

http://orcid.org/0000-0003-1727-7842 


\section{Study Highlights}

Administrating antiviral agents during late pregnancy can effectively reduce maternal hepatitis B virus-DNA levels and successfully prevent perinatal transmissions. However, mother-to-child transmission can still occur despite the suppression of maternal viral load. Postpartum biochemical flare is likely to occur in mothers who had previously been treated for chronic hepatitis B and discontinued antivirals for pregnancy. Hepatitis B e antigen seroconversion can occur in mothers who undergo persistent antiviral therapy or severe hepatitis after delivery.

\section{INTRODUCTION}

Chronic hepatitis B (CHB) affects 240 million individuals worldwide and is highly prevalent in East Asia and sub-Saharan Africa.' Approximately $50 \%$ of CHB patients acquire the virus perinatally from infected mothers, and most of these patients become chronically infected. ${ }^{2}$ More than 686,000 people die every year due to complications of $\mathrm{CHB}$, including cirrhosis and liver cancer. ${ }^{3}$ Therefore, the prevention of perinatal transmission remains an important target for the global eradication of CHB.

Despite highly effective active and passive immune prophylaxis, the perinatal transmission of hepatitis B virus (HBV) is not completely prevented. The main causes of immunoprophylactic failure are maternal high viral load and positivity for the hepatitis B e antigen (HBeAg). ${ }^{4}$ Specifically, children from mothers with viral loads of 6 log copies/mL or more have a significant risk of perinatal transmission of HBV. ${ }^{5}$ Therefore, American Association for the Study of Liver Diseases (AASLD) guidelines for treatment of chron- ic hepatitis B recommends considering antiviral therapy in $\mathrm{HBsAg-}$ positive pregnant women with an HBV DNA level >200,000 IU/ $\mathrm{mL}$ to reduce the risk of mother-to-child transmission (MTCT) of HBV. ${ }^{6}$

With the advent of vaccination programmes, HBsAg positivity has decreased from $10 \%$ to $3.8 \%$ in the Korean population since 1980. However, Korea is still classified as an intermediate HBV endemic area. ${ }^{7}$ To our knowledge, there are limited data evaluating antiviral treatment during late pregnancy to prevent perinatal transmission of HBV in Korea. Moreover, maternal long-term outcomes in terms of virological and biochemical changes after delivery are rarely reported. Therefore, we performed this retrospective study to evaluate the impact of antiviral therapy in reducing maternal viral loads and preventing MTCT during pregnancy. Additionally, we analyzed maternal data to determine long-term, postdelivery outcomes of patients who did not receive antiviral agents.

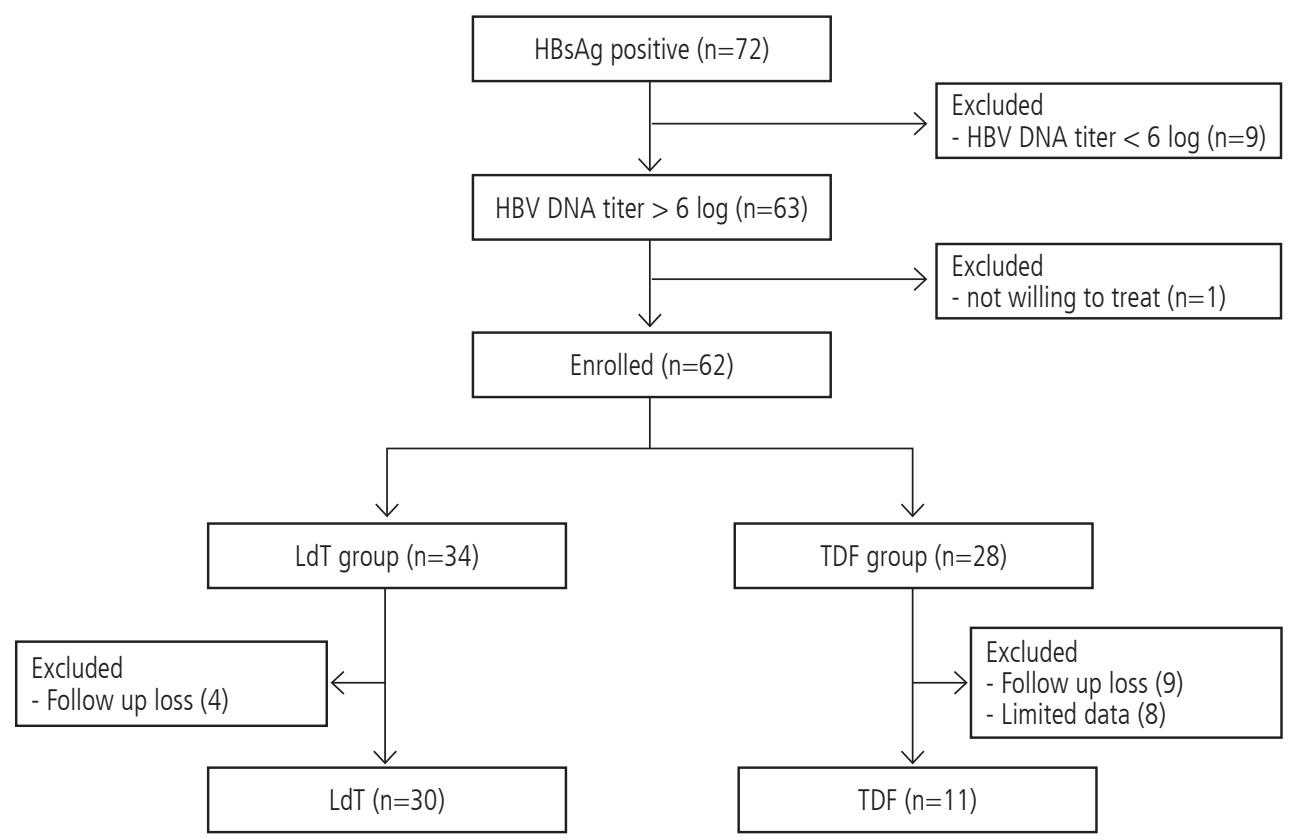

Figure 1. Flow chart of patients. Forty-one pregnant women with chronic hepatitis B virus were analyzed. Thirty pregnant women received telbivudine, and eleven received tenofovir during late pregnancy. $\mathrm{HBsAg}$, hepatitis B surface antigen; HBV, hepatitis B virus; LdT, telbivudine; TDF, tenofovir. 


\section{MATERIALS AND METHODS}

\section{Study population}

We retrospectively reviewed the medical records of chronic hepatitis B-infected pregnant women who had been followed at six tertiary hospitals of The Catholic University of Korea, between January 2011 and December 2015. The exclusion criteria were as follows: HBV DNA levels less than 6 log copies/mL before initiation of antiviral agents; co-infection of human immunodeficiency virus or hepatitis C virus; and any clinical evidence of pregnancyrelated complications (Fig. 1). Baseline demographic data, gestational age at the initiation of antiviral therapy, the duration of antiviral treatment until delivery, and the types of antiviral agents used were recorded.

\section{Study protocol}

Either tenofovir or telbivudine was administered to pregnant women once daily, starting from gestational week 28-34 until delivery. HBeAg, HBV DNA, and alanine aminotransferase (ALT) levels in the mothers were ascertained in the mothers prior to initiating antiviral agents. The mothers were then followed serially on the day of delivery, 3 months postpartum and more than 1 year after. All of the infants received hepatitis $B$ immune globulin $0.5 \mathrm{~mL}$ within 24 hours of birth and hepatitis $B$ vaccine at 0,1 , and 6 months. After 7 months of age, HBsAb positivity was tested. This study protocol was approved by the Institutional Review Board/Ethics Committee of Seoul St. Mary's Hospital of the Catholic University of Korea (XC17REDI0033). Informed consent was not required because of the retrospective study design.

Severe postpartum hepatitis, referred to as biochemical flare, was defined as ALT levels greater than five-fold the upper limit of

Table 1. Baseline characteristics of the patients

\begin{tabular}{|c|c|c|c|c|}
\hline & Total & Telbivudine & Tenofovir & $P$-value \\
\hline Number & 41 & 30 & 11 & \\
\hline Age (years) & $32(22-40)$ & $32(22-40)$ & $32(29-36)$ & 0.441 \\
\hline Prior pregnancy $(n, \%)$ & $12(29.2)$ & $9(30.0)$ & $3(27.2)$ & 0.989 \\
\hline Gestational week at initiation Tx. & $31(28-34)$ & $32(28-34)$ & $31(28-33)$ & 0.344 \\
\hline \multicolumn{5}{|l|}{ CBC } \\
\hline WBC $(/ \mu \mathrm{L})$ & $8,460(4,850-13,160)$ & $8,130(4,850-11,840)$ & $8,680(6,410-13,160)$ & 0.156 \\
\hline $\mathrm{Hb}(\mathrm{g} / \mathrm{dL})$ & $12(10.5-14.6)$ & $11.9(10.5-14.6)$ & $12.1(10.6-13.8)$ & 0.805 \\
\hline Hct $(\%)$ & $36(31.2-44.0)$ & $36(31.2-44.0)$ & $35.35(31.3-39.6)$ & 0.577 \\
\hline 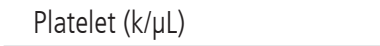 & $198(63-282)$ & $199.5(63-282)$ & $197(119-276)$ & 0.695 \\
\hline \multicolumn{5}{|l|}{ Blood chemistry } \\
\hline BUN (mg/dL) & $7.6(4.4-12.2)$ & $7.7(4.4-10.5)$ & $7.3(5.3-12.2)$ & 0.516 \\
\hline Creatinine (mg/dL) & $0.5(0.35-0.82)$ & $0.49(0.37-0.82)$ & $0.51(0.35-0.69)$ & 0.929 \\
\hline Protein (g/dL) & $6.3(5.7-7.3)$ & $6.2(5.7-7.3)$ & $6.5(6.3-7.3)$ & 0.012 \\
\hline Albumin (g/dL) & $3.6(2.9-4.19)$ & $3.6(2.9-4.19)$ & $3.6(3.4-4.0)$ & 0.869 \\
\hline AST (U/L) & $23(11-597)$ & $22(11-597)$ & $24(18-211)$ & 0.315 \\
\hline$\geq 40 \mathrm{U} / \mathrm{L}(\mathrm{n}, \%)$ & $10(24.3)$ & $7(23.3)$ & $3(27.2)$ & \\
\hline $\mathrm{ALT}(\mathrm{U} / \mathrm{L})$ & $21(10-645)$ & $10(19.5-645)$ & $22(13-234)$ & 0.495 \\
\hline$\geq 40 \mathrm{U} / \mathrm{L}(\mathrm{n}, \%)$ & $12(29.2)$ & $8(26.6)$ & $4(36.3)$ & \\
\hline Total bilirubin (mg/dL) & $0.4(0.1-1.12)$ & $0.4(0.1-1.08)$ & $0.38(0.3-1.12)$ & 0.455 \\
\hline \multicolumn{5}{|l|}{ Viral Markers } \\
\hline HBeAg-positivity (n, \%) & 36 & $28(93.3)$ & $8(72.7)$ & \\
\hline \multirow[t]{2}{*}{ HBV DNA (copies/mL) } & $467,928,000$ & $453,988,000$ & $546,000,000$ & 0.532 \\
\hline & $(4,462,080-3,125,097,607)$ & $(11,736,105-2,450,560,000)$ & $(4,462,080-3,125,097,607)$ & \\
\hline log HBV DNA (log copies/mL) & $8.67(6.6-9.49)$ & $8.64(7-9.3)$ & $8.7(6.6-9.49)$ & 0.739 \\
\hline
\end{tabular}

Values are presented as median (range) or $\mathrm{n}(\%)$ unless otherwise indicated.

Tx., treatment; CBC, complete blood count; WBC, white blood cell; Hb, hemoglobin; Hct, hematocrit; BUN, blood urea nitrogen; AST, aspartate aminotransferase; ALT, alanine aminotransferase; $\mathrm{HBeAg}$, hepatitis $\mathrm{B}$ e antigen; $\mathrm{HBV}$, hepatitis $\mathrm{B}$ virus. 
normal (ULN, $40 \mathrm{IU} / \mathrm{L})$. Because of the retrospective nature of the study, antiviral agents were initiated at different gestational ages (GAs). Therefore, we used the term "late pregnancy" rather than "third trimester". To detect the effect of antiviral agents in preventing MTCT, the primary outcome was HBsAb positivity of the infants after 7 months of age. To assess maternal long-term outcome, the secondary outcomes were postpartum virological and biochemical changes in mothers who did not receive antiviral agents.

\section{Laboratory analysis}

HBV DNA levels were determined using a quantitative real-time polymerase chain reaction (PCR) assay (Abbott RealTime HBV, Abbott m2000sp System; Abbott Molecular Inc., Chicago, IL, USA), according to the manufacturer's instructions (at detection limits of 34 copies $/ \mathrm{mL}$ ). A radioimmunoassay method was used to measure serum $\mathrm{HBeAg}$, in accordance with manufacturer's protocol (Abbott Laboratories, Chicago, IL, USA).

\section{Statistical analysis}

Categorical data were expressed as numbers or percentages. Continuous data were expressed as the median (range). Logarithmical transformation was performed for HBV DNA levels. The Mann-Whitney $U$-test was used to evaluate continuous data, and Fisher's exact test was applied to categorical data. The Wilcoxon signed-rank test was used for testing changes in maternal HBV DNA levels. A $P$-value $<0.05$ was considered statistically significant. The analysis was conducted using SPSS software, version 23 (IBM Corp., Armonk, NY, USA).

\section{RESULTS}

\section{Baseline characteristics}

Between January 2011 and December 2015, 72 pregnant women with $\mathrm{CHB}$ visited for follow up. Of these, nine mothers had pre-

Table 2. Clinical outcomes after antiviral treatment in HBV-infected pregnant women

\begin{tabular}{|c|c|c|c|}
\hline & Total & Telbivudine & Tenofovir \\
\hline Number & 41 & 30 & 11 \\
\hline Tx. duration (days) & $57(23-100)$ & $56.5(23-100)$ & $58(37-83)$ \\
\hline \multicolumn{4}{|l|}{ Blood chemistry } \\
\hline Albumin (g/dL) & $3.5(2.6-4.2)$ & $3.55(2.6-4.2)$ & $3.4(3.2-3.6)$ \\
\hline $\mathrm{AST}(\mathrm{U} / \mathrm{L})$ & $24(12-118)$ & $23(12-118)$ & $27(17-77)$ \\
\hline$\geq 40 \mathrm{U} / \mathrm{L}(\mathrm{n}, \%)$ & $7(17.0)$ & $4(13.3)$ & 3 \\
\hline $\mathrm{ALT}(\mathrm{U} / \mathrm{L})$ & $21(5-152)$ & $20(5-152)$ & $22(15-101)$ \\
\hline$\geq 40 \mathrm{U} / \mathrm{L}(\mathrm{n}, \%)$ & $8(19.5)$ & $4(13.3)$ & 4 \\
\hline Total bilirubin (mg/dL) & $0.495(0.1-1.4)$ & $0.48(0.1-1.4)$ & $0.5(0.27-1.02)$ \\
\hline \multicolumn{4}{|l|}{ Viral markers } \\
\hline HBeAg-positivity (n) & 36 & 28 & 8 \\
\hline HBV DNA (copies/mL) & $\begin{array}{c}116,400 \\
(116-3,683,825)\end{array}$ & $\begin{array}{c}135,939 \\
(116-2,467,680)\end{array}$ & $\begin{array}{c}77,451 \\
(367-3,683,825)\end{array}$ \\
\hline log HBV DNA (log copies/mL) & $5.06(2.06-6.5)$ & $5.08(2.06-6.39)$ & $4.88(2.5-6.5)$ \\
\hline \multicolumn{4}{|l|}{ Obstetric outcomes } \\
\hline \multicolumn{4}{|l|}{ Type of birth } \\
\hline Caesarean section $(\mathrm{n}, \%)$ & $7(17.0)$ & $6(20.0)$ & $1(9.0)$ \\
\hline Vaginal $(n, \%)$ & $34(83.0)$ & $24(80.0)$ & $10(91.0)$ \\
\hline Twin & 2 & 2 & 0 \\
\hline \multicolumn{4}{|l|}{ Fetal outcome } \\
\hline Antibody positivity (n, \%) & $39(95.1)$ & $30(100)$ & $9(81.8)$ \\
\hline
\end{tabular}

Values are presented as median (range) or $n$ (\%) unless otherwise indicated.

Tx., treatment; AST, aspartate aminotransferase; ALT, alanine aminotransferase; HBeAg, hepatitis B e antigen; HBV, hepatitis B virus. 
treatment HBV DNA less than 6 log copies/mL, one mother was not willing to be treated, thirteen mothers had no follow-up data for HBV DNA levels after antiviral treatment, and eight mothers did not have anti-HBs antibody positivity checked in their infants. As a result, the data from 41 pregnant women were analyzed in this study. The baseline characteristics of the study subjects are shown in Table 1. Overall, the median age at delivery was 32 (22-40) years, and the median gestational week at the initiation

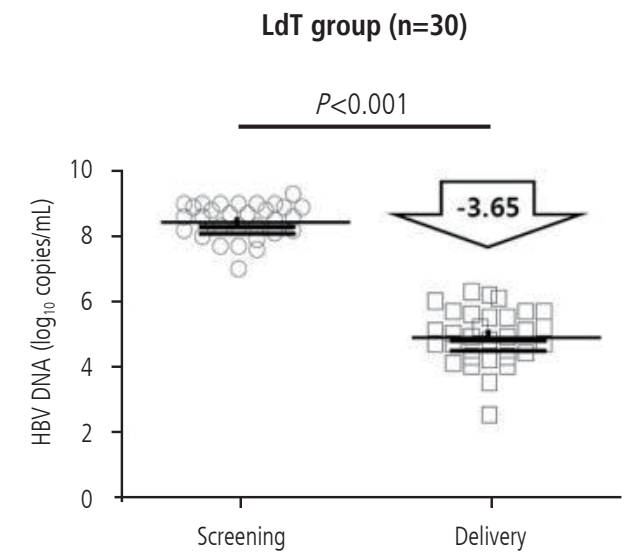

\section{A}

$$
\text { Median: } 56 \text { days }
$$

of the antiviral agent was 31 (28-34). Baseline ALT and HBV DNA levels were 21 (10-645) IU/mL and 8.67 (6.60-9.49) log copies/mL, respectively.

\section{Virological and biochemical changes during treatment}

Thirty pregnant women received telbivudine, and eleven re-

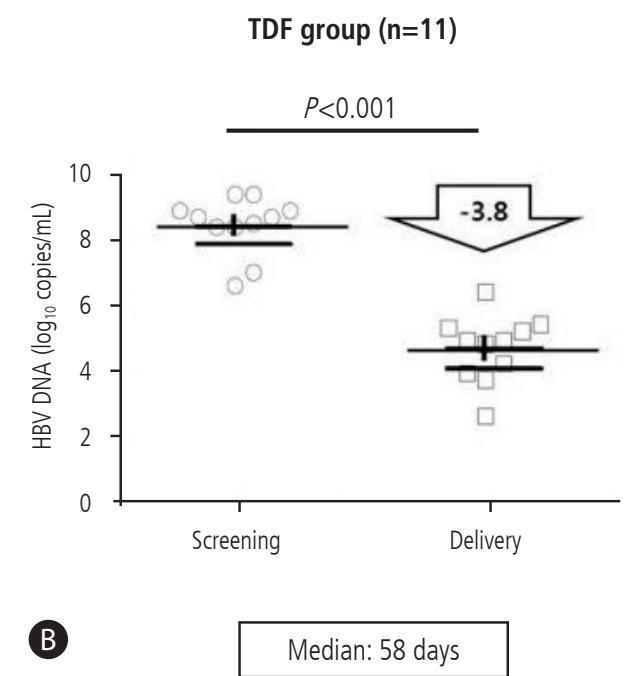

Figure 2. Virologic efficacy of antepartum antiviral therapy. (A) In the telbivudine-treated group, the median baseline HBV DNA loads were 8.64 (7.009.30) log copies $/ \mathrm{mL}$, falling to 5.08 (2.06-6.39) log copies $/ \mathrm{mL}$ at delivery, a mean reduction of $3.65 \mathrm{log}$ copies $/ \mathrm{mL}(P<0.001)$. (B) In patients treated with tenofovir, the median baseline HBV DNA was 8.7 (6.60-9.49) log copies/mL, which decreased to 4.88 (2.5-6.5) log copies/mL at delivery, with a mean reduction of $3.8 \log$ copies $/ \mathrm{mL}(P<0.001)$. HBV, hepatitis B virus; LdT, telbivudine; TDF, tenofovir.

Table 3. Clinical characteristics of patients in whom MTCT occurred despite active and passive immune prophylaxis

\begin{tabular}{|c|c|c|}
\hline & Case 1 & Case 2 \\
\hline Age & 34 & 29 \\
\hline Antiviral drug & TDF & TDF \\
\hline Previous exposure to antiviral drugs & No & No \\
\hline HBeAg positivity & Positive & Negative \\
\hline \multicolumn{3}{|l|}{ HBV DNA levels ( $\log _{10}$ copies/mL) } \\
\hline At screening & 9.4 & 8.7 \\
\hline At delivery & 6.4 & 3.7 \\
\hline Duration of treatment (days) & 46 & 37 \\
\hline Initiation of treatment (GA, week) & $33+3$ & $33+2$ \\
\hline Delivery (GA, week) & $40+0$ & $38+4$ \\
\hline Mode of delivery & Vaginal delivery & $\begin{array}{c}\text { Emergent caesarean } \\
\text { d/t fetal distress }\end{array}$ \\
\hline Amniocentesis & No record & No record \\
\hline Sex of newborn baby & Female & Male \\
\hline Congenital anomaly & No & No \\
\hline Medical record & & Biting nipple and bleeding \\
\hline
\end{tabular}

MTCT, mother-to-child transmission; TDF, tenofovir disoproxil fumarate; HBeAg, hepatitis B e antigen; HBV, hepatitis B virus; GA, gestational age; d/t, due to. 
ceived tenofovir during late pregnancy (Table 2). The median treatment durations of telbivudine and tenofovir were 56 (23100) days and 58 (37-83) days, respectively. The median HBV DNA level fell from $8.67(6.60-9.49) \log$ copies $/ \mathrm{mL}$ at baseline to $5.06(2.06-6.50) \log$ copies $/ \mathrm{mL}$ at delivery. In the telbivudinetreated group, the median baseline HBV DNA loads were 8.64 (7.00-9.30) log copies/mL, falling to 5.08 (2.06-6.39) log copies $/ \mathrm{mL}$ at delivery, a mean reduction of $3.65 \mathrm{log}$ copies $/ \mathrm{mL}(P<0.001)$. In patients treated with tenofovir, the median baseline HBV DNA was $8.7(6.60-9.49) \log$ copies $/ \mathrm{mL}$, which decreased to 4.88 (2.5-6.5) log copies/mL at delivery, with a mean reduction of 3.8 log copies/mL $(P<0.001)$ (Fig. 2).

\section{Safety and efficacy of antiviral treatment to prevent MTCT}

No mother discontinued the antiviral agent due to adverse events. No infant was identified with any congenital anomaly.
Overall, the use of antiviral agents during late pregnancy reduces the rate of MTCT to less than $5 \%$ as defined by infant anti-HBs antibody seropositivity. There was no MTCT in telbivudine-treated group. However, perinatal transmission was observed in two infants in tenofovir treated group despite a good virological response of their mothers (Table 3).

One of these infants was born to a 34-year-old, HBeAg-positive mother whose HBV DNA titer was $9.4 \log$ copies $/ \mathrm{mL}$ at screening and $6.4 \log$ copies $/ \mathrm{mL}$ at delivery. The antiviral therapy was initiated at 33 weeks and 3 days of $\mathrm{GA}$, and the duration of antiviral treatment was 46 days. The mode of delivery was spontaneous vaginal delivery, and no invasive procedure was performed during pregnancy, such as amniocentesis. The other infant who tested positive was born to a 29-year-old, HBeAg-negative mother with viral loads at screening and delivery of $8.7 \log$ copies $/ \mathrm{mL}$ and 3.7 $\log$ copies $/ \mathrm{mL}$, respectively. The antiviral agents were administered at 33 weeks and 2 days of GA, and the duration of antiviral therapy was 37 days. Because of unexpected fetal distress, an

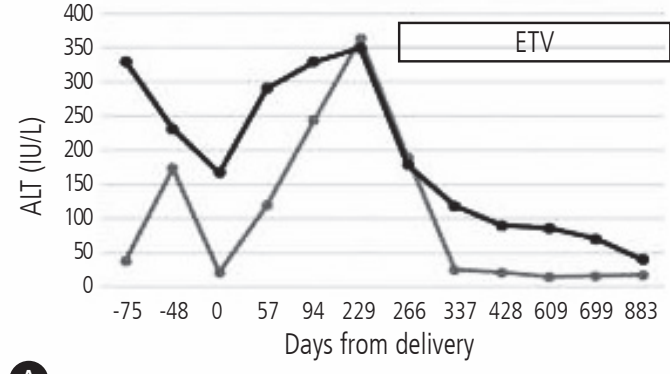

A$$
\rightarrow \text { ALT } \rightarrow \text { DNA }
$$
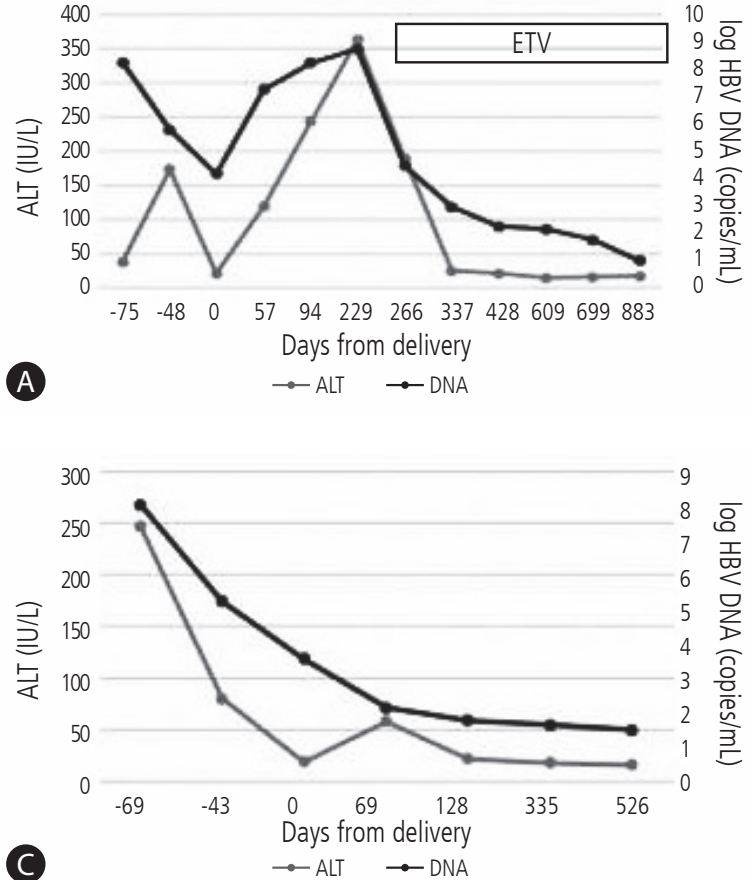
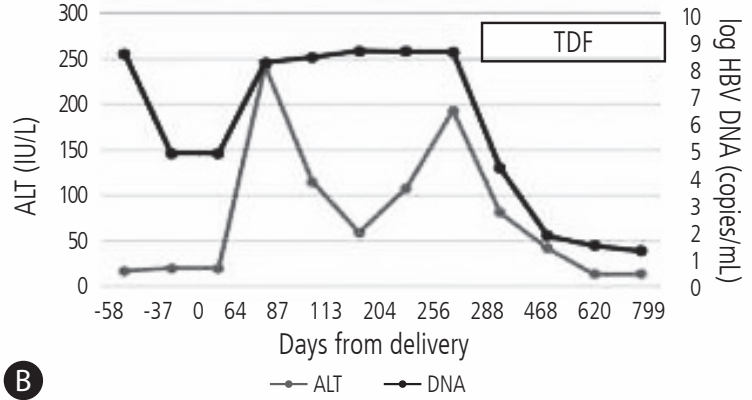

B

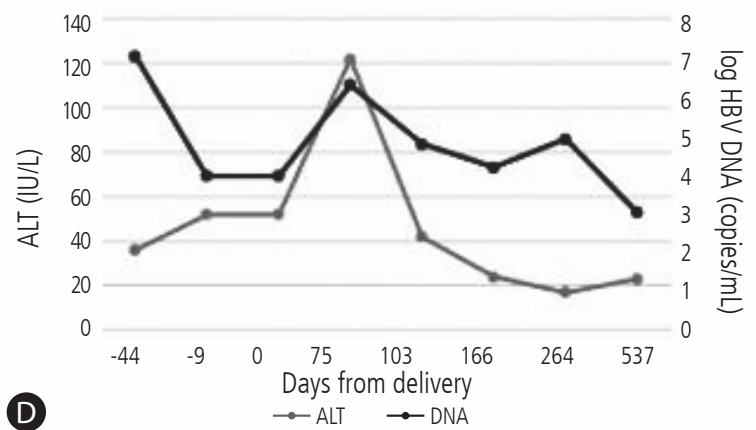

Figure 3. Maternal virologic and biochemical changes after withdrawal. (A) One mother was 33 years old, HBeAg-positive, and nulliparous. On day 229 postpartum, she began treatment with entecavir due to biochemical flare. (B) The other mother was 34 years old, HBeAg-positive, and nulliparous. On postpartum day 256, tenofovir was initiated due to biochemical flare. (C) A mother who was 29 years old, HBeAg-positive, nulliparous, and used telbivudine in late pregnancy experienced a temporary elevation in ALT level and showed spontaneously decreasing HBV DNA level. (D) A 32-year-old mother who was HBeAg-negative, nulliparous, and used tenofovir used in late pregnancy experienced a temporary elevation in both HBV DNA and ALT levels after delivery and exhibited a spontaneous decrease in HBV DNA level. HBeAg, hepatitis B e antigen; ALT, alanine aminotransferase; HBV, hepatitis B virus; ETV, entecavir; TDF, tenofovir. 
emergent Caesarean section (CS) was necessary at 38 weeks and 4 days of GA. Similarly, no medical record revealed an invasive procedure during pregnancy. However, the mother recalled that the infant had occasionally bitten the nipples during breast feeding, resulting in bleeding.

\section{Maternal virologic and biochemical changes after the withdrawal}

Only one mother had continued antiviral agent after giving birth. Forty of 41 mothers ceased antiviral treatment at the time of delivery. Of these, 11 mothers were followed for more than 12 months. Therefore, we analyzed the serologic changes of these 11 mothers after delivery. Two (18.2\%) mothers experienced biochemical flare and were re-administered an antiviral agent. One mother was 33 years old, HBeAg positive and nullipara. Before the pregnancy, she received interferon therapy to treat chronic hepatitis but failed. Oral antiviral treatment was planned, but it was decided to delay treatment after pregnancy. The HBV DNA load was $8.2 \log$ copies $/ \mathrm{mL}$ in the third trimester, and telbivudine was administered for 75 days before delivery. At delivery, the maternal HBV DNA load was 4.18 log copies $/ \mathrm{mL}$, and the AST and ALT levels were 21 and $25 \mathrm{IU} / \mathrm{mL}$, respectively. On day 57 postpartum, the HBV DNA load was elevated to 7.2 log copies $/ \mathrm{mL}$, and the AST levels were increased to $119 \mathrm{IU} / \mathrm{mL}$ and ALT to 101 $\mathrm{IU} / \mathrm{mL}$. The mother was followed up without antiviral drugs. However, the HBV DNA load was increased to 8.7 log copies $/ \mathrm{mL}$ and the AST and ALT levels to 363 and $342 \mathrm{IU} / \mathrm{mL}$, respectively, on day 229 postpartum. Consequently, the mother initiated treatment with entecavir (Fig. 3A).

The other mother who experienced biochemical flare was 34 years old, HBeAg positive and nulliparous. She had been treated with lamivudine for three years, after which resistance developed. Therefore, she was treated with entecavir for more than 3 years and stopped during pregnancy. Tenofovir was administered in the third trimester of pregnancy when the maternal HBV DNA load was $8.5 \log$ copies $/ \mathrm{mL}$. Sixty-four days after delivery, the maternal HBV DNA load had increased to 8.2 log copies/mL, with AST and ALT levels of 242 and $101 \mathrm{IU} / \mathrm{mL}$, respectively. On day 113 postpartum, the HBV DNA load was unchanged at $8.6 \mathrm{log}$ copies $/ \mathrm{mL}$, but the AST and ALT levels had decreased to 59 and $36 \mathrm{IU} / \mathrm{mL}$, respectively. No antiviral treatment was administered. However, tenofovir was initiated 256 days after delivery, at which time the HBV DNA load had elevated to 8.6 log copies/mL, AST to $193 \mathrm{IU} / \mathrm{mL}$, ALT to $97 \mathrm{IU} / \mathrm{mL}$ (Fig. 3B).
Three of the remaining 9 mothers had minimal changes in ALT levels. The other six mothers exhibited temporarily elevated ALT levels with increased HBV DNA levels, but these abnormalities improved without treatment. Two of the six mothers who experienced temporary elevations in ALT levels showed a tendency towards decreased to HBV DNA levels. One 29-year-old, HBeAgpositive, and nulliparous mother received telbivudine in late pregnancy, experiencing a temporary elevation in ALT levels. After delivery, she showed a spontaneous tendency of HBV DNA reduction (Fig. 3C). The other mother was 32 years old, HBeAg negative, and nulliparous. This mother received tenofovir used in late pregnancy and experienced a temporary elevation in both HBV DNA and ALT levels after delivery. Likewise, this patient showed a spontaneous decrease in HBV DNA level (Fig. 3D).

Postpartum $\mathrm{HBeAg}$ seroconversion was found in four mothers. Two mothers each were in the tenofovir (18.18\%) and telbivudine groups (6.66\%) $(P=0.16)$. Three mothers experienced postpartum ALT level elevation higher than three- to five-fold the ULN of ALT levels. The other mother continued to take tenofovir after delivery and consequently did not experience postpartum ALT elevation. One mother, who experienced postpartum biochemical flare, did not receive antiviral therapy but exhibited $\mathrm{HBeAg}$ seroconversion. The other two mothers experienced ALT flares (greater than fivefold the ULN of ALT levels), were treated with either entecavir or tenofovir, and achieved HBeAg seroconversion.

\section{DISCUSSION}

It is recognized that modes of MTCT are intrauterine infection, peripartum infection, and postnatal infection. Nearly all perinatal transmission of HBV occurs during delivery. ${ }^{8}$ To a lesser extent, maternal transmission takes place intrauterine or postnatally. Administering passive and active prophylaxis has reduced the rate of perinatal transmission to less than $10 \%$. Immune prophylaxis failure is known to occur primarily in mothers with higher viral loads and HBeAg positivity. ${ }^{9}$ Therefore, several studies have been performed to evaluate the efficacy of antiviral agents to reduce maternal HBV viral loads and to further reduce the MTCT rates of HBV.

Our study demonstrated the efficacy of administering antiviral agents during late pregnancy to prevent the MTCT of HBV. In accordance with a recently reported systematic review and metaanalysis, ${ }^{10}$ antiviral therapy improved HBV suppression and reduced MTCT in highly viremic pregnant women. Most of the 
infants $(95.3 \%$, 41/43) exhibited anti-HBs antibody positivity. All of the pregnant women experienced a HBV DNA reduction to near or less than $6 \log$ copies $/ \mathrm{mL}$ near the day of delivery, regardless of baseline HBV DNA levels and the types of antiviral drugs used such as telbivudine and tenofovir.

Studies of viral kinetics have shown that the administration of telbivudine or tenofovir for 3 weeks reduces the serum HBV DNA load by $2.9 \log$ copies $/ \mathrm{mL}$. After 12 weeks, the viral DNA load of the telbivudine treatment group decreased by $3.9 \log$ copies $/ \mathrm{mL}$ and that of the tenofovir group decreased by $4.2 \log$ copies $/ \mathrm{mL} .{ }^{11}$ In our study, the median duration of antiviral treatment was 58 days, and the overall reduction of maternal HBV DNA levels was approximately $3.9 \log$ copies $/ \mathrm{mL}$, similar antiviral effectiveness in HBV DNA reduction and viral kinetics was also observed. Therefore, we suggest that initiating antiviral agent in the third trimester can result in a desirable maternal viral reduction at delivery and successful prevention of the MTCT of hepatitis B virus. Moreover, seven pregnant women treated with telbivudine for fewer than 40 days successfully prevented MTCT, reducing HBV DNA levels below 6 log copies $/ \mathrm{mL}$ at delivery.

As with our research results, despite a sufficient suppression of viral load with tenofovir to prevent MTCT, perinatal transmission of hepatitis B virus can still occur. Several cases of failure to prevent perinatal transmission have been reported. In a prospective study, two cases of MTCT were confirmed in the tenofovir-treated group. The authors suspected that the mechanisms of MTCT were trans-placental transmission in one case and postnatal transmission in the other. ${ }^{12}$ Another group also reported one case of MTCT despite suppression of viral load with tenofovir, suggesting the possibility of trans-placental or germ line transmission of hepatitis $B$ virus. ${ }^{13}$ Recently, the majority of perinatal transmission of hepatitis $B$ virus has been prevented by immune prophylaxis. However, it is not well understood how uncommon situations, such as intrauterine infection, lead to MTCT. ${ }^{14}$

In our study, two infants who were negative for HBsAb at 12 months were confirmed to be infected with the hepatitis $B$ virus. One infant was born to a 34-year-old mother who had a HBV DNA titer at delivery of $6.4 \log$ copies $/ \mathrm{mL}$. It has been reported that the risk of perinatal transmission is significantly increased when maternal the HBV DNA load is greater than 7 log copies $/ \mathrm{mL}^{5}$ However, a study published in China reported that the probability of perinatal transmission was $3.2 \%$ when the maternal HBV DNA titer was higher than $6 \log$ copies $/ \mathrm{mL}$, even with active and passive immune prophylaxis. ${ }^{9} \mathrm{~A}$ recently published meta-analysis also reported that probability of perinatal transmission was signifi- cantly increased when the maternal HBV DNA titer was higher than $6 \log$ copies/mL, even with active and passive immune prophylaxis. ${ }^{10}$ In the AASLD guidelines, MTCT was found to be significantly elevated at maternal HBV DNA titer above $6 \log$ copies $/ \mathrm{mL}{ }^{6}$ Therefore, in this case, insufficient viral suppression below 6 log copies $/ \mathrm{mL}$ may be one of the most important risk factors for perinatal transmission. However, the reason for MTCT in this infant could not be definitively determined. Instead, we suggest other possible reasons of the failure to prevent MTCT in this mother. First, although there is no objective data to prove, we also suspect that the possibility of trans-placental or germ line transmission of hepatitis B virus. Second, it is possible that the duration of antiviral medication should be increased for some mothers. As mentioned above, approximately 8 weeks were required to reduce HBV DNA titer by 3.5 log copies $/ \mathrm{mL}$ in hepatitis B-infected pregnant women. ${ }^{11}$ Therefore, considering viral kinetics, highly viremic pregnant women (>9 log copies/mL of HBV DNA titer) might require additional treatment time with antiviral agents. ${ }^{15}$

The other infant was born to a 29-year-old mother whose HBV DNA titerat delivery was $3.7 \log$ copies $/ \mathrm{mL}$, which is considered sufficiently low to prevent vertical transmission during delivery. ${ }^{6}$ However, unexpected fetal distress required an emergency $\mathrm{CS}$ at 40 weeks of GA. Generally, the mode of delivery did not increase the risk of MTCT if maternal HBV DNA levels were under 6 log copies $/ \mathrm{mL}$ at delivery. ${ }^{16}$ Therefore, we believe that the emergency CS in our patient was not the cause of the MTCT. However, the medical record showed that the infant occasionally bit the nipples during breastfeeding, resulting in bleeding. At post-partum 13 weeks, maternal blood was highly viremic: HBV DNA titer higher than 8 log copies $/ \mathrm{mL}$. It is well known that breastfeeding cannot cause MTCT if effective active and passive immune prophylaxis is used. ${ }^{17}$ However, it is the general rule that the mothers must take care of their nipples to avoid cracking or bleeding because HBV is transmitted through the blood. ${ }^{18} \mathrm{HBV}$ is very infectious and is able to easily transmit through mucosal breaks in the mouth. However, as the infant in our case had received active and passive immuneprophylaxis, the probability of postnatal transmission was very low. Nevertheless, some studies have suggested the possibility of postnatal transmission in non-responders or low-titer responders to HBV vaccination due to certain human leukocyte antigen alleles ${ }^{12,19}$ We do not know whether the infant in this case fell into one of these categories. Therefore, we cannot completely exclude this possibility considering blood exposure that directly occurred during breast feeding.

Reactivation of hepatitis B after delivery is a concern in the 
types of cases considered in this study. In our study, mothers discontinued antiviral treatment shortly after delivery. In the AASLD guidelines, rather than being limited to three months after delivery, the guidelines noted that antiviral therapy was discontinued at birth to 3 months postpartum in most of the studies. Moreover, because most mothers in our study wanted breastfeeding, they stopped the antiviral agents on the day of delivery. Two of 11 mothers who had been observed for more than 1 year after childbirth experienced viral reactivation and initiated antiviral treatment. These two mothers received antiviral treatment prior to pregnancy and ceased therapy during pregnancy. Therefore, mothers who require chronic hepatitis $B$ treatment before pregnancy are more likely to experience biochemical flare after childbirth. Even without continuing antiviral medication, there were two mothers with a sustained reduction in HBV DNA after delivery. Unfortunately, we were not able to identify the characteristics that led to these outcomes. HBeAg seroconversion was confirmed in four mothers, although there was no significant difference regarding the type of antiviral agent used. It was reported that seroconversion can occur well below $3 \times 10^{7} \mathrm{IU} / \mathrm{mL}$ of HBV DNA. ${ }^{20}$ However, our results suggest that $\mathrm{HBeAg}$ seroconversion was more likely to be experienced in patients treated with antiviral therapy or who experienced severe hepatitis.

This study has several limitations. Because this study was retrospectively analyzed, there are lack of specific data. In addition, the cause of MTCT in the TDF-treated mothers was not found clearly. Nevertheless, this study suggests that it was possible to prevent the perinatal transmission of hepatitis B virus by administering antiviral agents to pregnant patients in Korea. In conclusion, administrating antiviral agents during late pregnancy can effectively reduce maternal HBV DNA levels and successfully prevent perinatal transmissions. However, MTCT can still occur despite the suppression of maternal viral load. The cause of MTCT in two cases of this study is unclear. Cautiously, the highly viremic pregnant women ( $>9$ log copies/mL of HBV DNA) might require additional treatment with antiviral agents. Postpartum biochemical flare is likely to occur in mothers who had previously been treated for chronic hepatitis B and discontinued antivirals for pregnancy. HBeAg seroconversion can occur in mothers who undergo persistent antiviral therapy or severe hepatitis after delivery.

\section{Authors' contribution}

Si Hyun Bae conceived of the project.

Si Hyun Bae, Jeong Won Jang, Chung-Hwa Park, Pil Soo Sung and Kwang II Seo made substantial contributions to the concep- tion, design and interpretation of data.

Si Hyun Bae, Hae Lim Lee, Hee Yeon Kim, Hye Ji Kim, Bo Hyun Jang and Chung-Hwa Park generated the data.

Si Hyun Bae, Chung-Hwa Park, Pil Soo Sung and Kwang II Seo wrote the manuscript.

Si Hyun Bae, Hae Lim Lee, Hee Yeon Kim, Hye Ji Kim, Pil Soo Sung, Bo Hyun Jang, Seung Kew Yoon, Jeong Won Jang, Jong Young Choi, Chung-Hwa Park, In-Yang Park, Juyoung Lee, Hyun Seung Lee, Sa-Jin Kim, Jung Hyun Kwon, U Im Chang, Chang Wook Kim, Se Hyun Jo, Young Lee, Fisseha Tekle and Jong-Hyun Kim participated in the design and coordination of the study and acquired the data.

All of the authors have read and approved the final manuscript.

\section{Acknowledgements}

This research was supported by a grant of the Korea Health Technology R\&D Project through the Korea Health Industry Development Institute (KHIDI), funded by the Ministry of Health \& Welfare, Republic of Korea (grant number: HI17C1050).

\section{Conflicts of Interest}

The authors declare they have no conflict of interest.

\section{REFERENCES}

1. Visvanathan K, Dusheiko G, Giles M, Wong ML, Phung N, Walker S, et al. Managing HBV in pregnancy. Prevention, prophylaxis, treatment and follow-up: position paper produced by Australian, UK and New Zealand key opinion leaders. Gut 2016;65:340-350.

2. Yogeswaran K, Fung SK. Chronic hepatitis B in pregnancy: unique challenges and opportunities. Korean J Hepatol 2011;17:1-8.

3. GBD 2013 Mortality and Causes of Death Collaborators. Global, regional, and national age-sex specific all-cause and cause-specific mortality for 240 causes of death, 1990-2013: a systematic analysis for the Global Burden of Disease Study 2013. Lancet 2015;385:117171.

4. Stevens CE, Neurath RA, Beasley RP, Szmuness W. HBeAg and antiHBe detection by radioimmunoassay: correlation with vertical transmission of hepatitis B virus in Taiwan. J Med Virol 1979;3:237-241.

5. Wen WH, Chang MH, Zhao LL, Ni YH, Hsu HY, Wu JF, et al. Motherto-infant transmission of hepatitis $B$ virus infection: significance of maternal viral load and strategies for intervention. J Hepatol 2013;59:24-30.

6. Terrault NA, Bzowej NH, Chang KM, Hwang JP, Jonas MM, Murad $\mathrm{MH}$, et al. AASLD guidelines for treatment of chronic hepatitis $\mathrm{B}$. 
Hepatology 2016;63:261-283.

7. Kim H, Shin AR, Chung HH, Kim MK, Lee JS, Shim JJ, et al. Recent trends in hepatitis $B$ virus infection in the general Korean population. Korean J Intern Med 2013;28:413-419.

8. World Health Organization. Guidelines for the prevention, care and treatment of persons with chronic hepatitis B infection. Geneva: World Health Organization, 2015:89-93.

9. Zou H, Chen Y, Duan Z, Zhang H, Pan C. Virologic factors associated with failure to passive-active immunoprophylaxis in infants born to HBsAg-positive mothers. J Viral Hepat 2012;19:e18-e25.

10. Brown RS Jr, McMahon BJ, Lok AS, Wong JB, Ahmed AT, Mouchli $M A$, et al. Antiviral therapy in chronic hepatitis $B$ viral infection during pregnancy: a systematic review and meta-analysis. Hepatology 2016;63:319-333.

11. Leung NW, Herrmann E, Lau GK, Chan HL, So TM, Zeuzem S, et al. Early viral kinetics with telbivudine, tenofovir or combination of both in immunotolerant patients with hepatitis B e antigen-positive chronic hepatitis B. Infect Dis Ther 2014;3:191-202.

12. Chen $\mathrm{HL}$, Lee $\mathrm{CN}$, Chang $\mathrm{CH}$, Ni YH, Shyu MK, Chen SM, et al. Efficacy of maternal tenofovir disoproxil fumarate in interrupting mother-to-infant transmission of hepatitis $B$ virus. Hepatology 2015;62:375-386.

13. Greenup AJ, Tan PK, Nguyen V, Glass A, Davison S, Chatterjee U, et al. Efficacy and safety of tenofovir disoproxil fumarate in pregnancy to prevent perinatal transmission of hepatitis B virus. J Hepatol
2014;61:502-507.

14. Cheung KW, Seto MT, Wong SF. Towards complete eradication of hepatitis $B$ infection from perinatal transmission: review of the mechanisms of in utero infection and the use of antiviral treatment during pregnancy. Eur J Obstet Gynecol Reprod Biol 2013;169:17-23.

15. Yang FS. Prevention of peripartum hepatitis B transmission. N Engl J Med 2016;375:1497.

16. Pan CQ, Zou HB, Chen Y, Zhang $X$, Zhang H, Li J, et al. Cesarean section reduces perinatal transmission of hepatitis $B$ virus infection from hepatitis B surface antigen-positive women to their infants. Clin Gastroenterol Hepatol 2013;11:1349-1355.

17. Yi P, Chen R, Huang Y, Zhou RR, Fan XG. Management of mother-tochild transmission of hepatitis $B$ virus: propositions and challenges. J Clin Virol 2016;77:32-39.

18. Navabakhsh B, Mehrabi N, Estakhri A, Mohamadnejad M, Poustchi $H$. Hepatitis $B$ virus infection during pregnancy: transmission and prevention. Middle East J Dig Dis 2011;3:92-102.

19. Yoon JH, Shin S, In JW, Chang JY, Song EY, Roh EY. Association of HLA alleles with the responsiveness to hepatitis $B$ virus vaccination in Korean infants. Vaccine 2014;32:5638-5644.

20. Hu Y, Feng Z, Liu J, Chen J, Zhang S, Zhou YH. Virological determinants of spontaneous postpartum e antigen seroconversion and surface antigen seroclearance in pregnant women infected with hepatitis B virus. Arch Med Res 2016:47:207-213. 